\title{
Expression of tissue factor in human cervical carcinoma tissue
}

\author{
XITONG ZHAO, CHU CHENG, JINHAI GOU, TAO YI, YANPING QIAN, XUE DU and XIA ZHAO \\ Department of Gynecology and Obstetrics, Key Laboratory of Obstetrics and Gynecology and \\ Pediatric Diseases and Birth Defects, The Ministry of Education, West China Second Hospital, \\ Sichuan University, Chengdu, Sichuan 610041, P.R. China
}

Received March 19, 2018; Accepted July 26, 2018

DOI: $10.3892 /$ etm.2018.6723

\begin{abstract}
The present study aimed to investigate tissue factor (TF) expression in cervical cancer and explore its association with disease progression. A total of 258 cervical cancer tissues and their adjacent normal tissues were collected between September 2014 and September 2016. TF expression was detected in the tissue samples by immunohistochemistry and western blot analysis. Associations between the expression of TF and clinical stage, differentiation status and metastasis of cancer cells were examined. The mean immunohistochemistry score of TF expression in cervical cancer tissues was $2.86 \pm 1.76$, which was significantly increased compared with the adjacent normal tissues $(0.28 \pm 0.45)$. The expression of TF was also significantly associated with the clinical stage, lymph node metastasis and distant metastasis of cancer cells. Immunohistochemistry staining and western blot analysis demonstrated that TF expression in cervical cancer tissues significantly increased as the clinical stage increased. TF expression in tumor tissues from patients with lymph node metastasis was significantly increased compared with samples from patients without lymph node metastasis. TF expression was also significantly increased in patients with distant metastasis compared with those without. In conclusion, TF is highly expressed in cervical cancer tissues and high expression of TF may enhance the invasion and metastasis of cervical cancer cells.
\end{abstract}

\section{Introduction}

Cervical cancer is one of the most common types of malignant tumor within gynecology. Behind Chile, China is the country with the second highest incidence of cervical cancer worldwide (1). In 2017, statistics released by the National Cancer Center (2) revealed that cervical cancer is the seventh

Correspondence to: Dr Xia Zhao, Department of Gynecology and Obstetrics, Key Laboratory of Obstetrics and Gynecology and Pediatric Diseases and Birth Defects, The Ministry of Education, West China Second Hospital, Sichuan University, 20 Renmin South Road, Chengdu, Sichuan 610041, P.R. China

E-mail: zhaoxiaticg@163.com

Key words: tissue factor, cervical cancer, metastasis most common malignant tumor in women living in urban areas and patients with cervical cancer are getting younger. Although the morbidity and mortality of cervical cancer have declined in recent years with advances in medical science and technology, there are 150,000 new cases of cervical cancer each year in China and $>80,000$ patients succumb to the disease (3). Similarly to other malignant tumors, invasion and metastasis of tumor cells are the primary cause of disease onset and mortality in patients with cervical cancer $(4,5)$.

Tissue factor (TF), also called platelet coagulation factor III, is an important member of the human coagulation factor family. TF initiates the blood coagulation cascade in vivo by binding with coagulation factor VII/VIIa $(6,7)$. It has been confirmed that the expression of TF is a biomarker for preoperative diagnosis and the prognosis of malignant tumors $(6,7)$. However, TF also affects the clinical progression of malignant tumors by affecting the proliferation, infiltration and metastasis of cancer cells (8-10); for this reason, TF is a potential target for the treatment of malignant tumors (11). However, few previous studies have reported the expression of TF in cervical cancer. In the present study, the expression of TF in cervical cancer was detected using immunohistochemistry and western blot analysis and its impact on the progression of cervical cancer was investigated.

\section{Patients and methods}

Study patients. A total of 258 pairs of fresh cervical cancer tissues and adjacent normal tissues $(>3 \mathrm{~cm}$ ) were collected at the West China Second Hospital (Chengdu, China) between September 2014 and September 2016. All cases of suspected cervical cancer were confirmed by postoperative pathology. Two pieces of fresh tissue, the size of soybean granules (diameter range, 4-6 mm), were removed from cervix during a pathological biopsy and preserved in liquid nitrogen $\left(-196^{\circ} \mathrm{C}\right)$. This surgery/biopsy was part of the patients' general treatment. The 258 patients with cervical cancer were aged 28-67 years with a median age of 45 years and a mean age of (46.2 \pm 7.9$)$ years. There were 203, 45 and 10 cases of squamous cell carcinoma, adenocarcinoma and adenosquamous carcinoma, respectively. Further clinical data, including clinical stage, tumor differentiation and HPV infection are listed in Table I. All patients included in the present study provided written informed consent prior to their inclusion and the study was approved by the Ethics Committee of West China Second Hospital. 
Instruments and reagents. Anti-TF (ab104513) and goat anti-rabbit immunoglobulin G H\&L antibodies (ab150084) were purchased from Abcam (Cambridge, UK). The VECTASTAIN ${ }^{\circledR}$ Elite ${ }^{\circledR}$ ABC kit (PK-6010; Vector Laboratories, Inc., Burlingame, CA, USA), radioimmunoprecipitation (RIPA) lysis liquid (strong), RNAiso Plus (RS0754), real-time fluorescence quantitative polymerase chain reaction (PCR) kit (RR066A; both Takara Bio, Inc., Otsu, Japan), the M-MLV Reverse Transcriptase RNase H Minus kit (M5301; Promega Corporation, Madison, WI, USA) and the BCA protein concentration determination kit (P0009; Beyotime Institute of Biotechnology, Haimen, China) were used in the present study.

The manual precision microtome (CUT4062; SLEE medical GmbH, Mainz, Germany), the light microscope (BX51; Olympus Corporation, Tokyo, Japan), polyvinylidene difluoride (PVDF) transfer membranes (GE Healthcare Life Sciences, Little Chalfont, UK) and real-time fluorescence quantitative PCR (Agilent Technologies, Inc., Santa Clara, CA, USA) were also used in the present study.

Immunohistochemistry. The fresh tissue sections were dehydrated using the following ascending alcohol series: Dehydration in $75 \%$ ethanol overnight, $85 \%$ ethanol for $3 \mathrm{~h}, 95 \%$ ethanol I for $1.5 \mathrm{~h}, 95 \%$ ethanol II for $1.5 \mathrm{~h}$, $100 \%$ ethanol I for $1 \mathrm{~h}$ and $100 \%$ ethanol II for $1 \mathrm{~h}$. Xylene was then added to the ethanol mixture for $25 \mathrm{~min}$ at room temperature and the samples were embedded in paraffin. A thermostat microtome was used to slice the tissues into sections $(1-2 \mu \mathrm{m})$ and they were rinsed three times with $0.01 \mathrm{M}$ preheated PBS (10 min each time). TF protein expression was detected by VECTASTAIN ${ }^{\circledR}$ Elite ${ }^{\circledR}$ ABC kit according to the manufacturer's protocol. The tissue sections were incubated overnight at $4^{\circ} \mathrm{C}$ with anti-TF antibodies (dilution 1:200) and then washed three times with PBS (10 min each time). PBS was used as the negative control instead of the primary antibodies. The sections were subsequently incubated with the goat anti-rabbit secondary antibodies (dilution 1:1,000) for $4 \mathrm{~h}$ at room temperature.

The TF immunohistochemistry results were assessed according to a previous study by Zhang et al (12). Initially, the percentage of positive cells $\leq 25 \%, 25-75 \%$ or $\geq 75 \%$, were scored 0,1 and 2 respectively. Next, the cells were stained colorless, light yellow, brown and tan, and scored $0,1,2$ and 3 respectively. The TF immunohistochemistry score was determined by multiplying the positive cell rate score with the staining intensity score. In the present study, a TF immunohistochemistry score of $\geq 4$ represented high expression and $<4$ represented low expression.

Western blot analysis. The tissue samples frozen in liquid nitrogen were removed and placed in a mortar. Using a liquid nitrogen-assisted freeze-thawing procedure, the tissue samples were ground rapidly. When the tissue was sufficiently ground, a RIPA lysate buffer with $1 \mathrm{mM}$ added phenylmethylsulfonyl fluoride, was used to extract the total proteins from the tissue. The RIPA lysate was transferred into an EP tube, resuspended, placed on ice for $10 \mathrm{~min}$ and centrifuged at $6,000 \mathrm{x} \mathrm{g}$ for $10 \mathrm{~min}$ in $4^{\circ} \mathrm{C}$. The supernatant was collected and added to a $20 \%$ SDS buffer solution to a final
Table I. Baseline data of the 258 patients with cervical cancer.

\begin{tabular}{|c|c|c|}
\hline Characteristic & Total & Percentage \\
\hline \multicolumn{3}{|l|}{ Age (years) } \\
\hline$\geq 45$ & 106 & 41.09 \\
\hline$<45$ & 152 & 58.91 \\
\hline \multicolumn{3}{|l|}{ Clinical classification } \\
\hline Squamous cell carcinoma & 203 & 78.69 \\
\hline Adenocarcinoma & 45 & 17.44 \\
\hline Adenosquamous carcinoma & 10 & 3.87 \\
\hline \multicolumn{3}{|l|}{ Tumor growth type } \\
\hline Cauliflower & 160 & 62.02 \\
\hline Nodular & 52 & 20.16 \\
\hline Ulcer & 28 & 10.85 \\
\hline Erosive & 18 & 6.97 \\
\hline \multicolumn{3}{|l|}{ Tumor size (cm) } \\
\hline$\leq 4$ & 77 & 29.84 \\
\hline$>4$ & 181 & 70.16 \\
\hline \multicolumn{3}{|l|}{ Differentiation } \\
\hline Poor & 47 & 18.22 \\
\hline Moderate & 77 & 29.84 \\
\hline High & 134 & 51.94 \\
\hline \multicolumn{3}{|l|}{ Lymph node metastasis } \\
\hline Yes & 153 & 59.30 \\
\hline No & 105 & 40.70 \\
\hline \multicolumn{3}{|l|}{ Distant metastasis } \\
\hline Yes & 142 & 55.04 \\
\hline No & 116 & 44.96 \\
\hline \multicolumn{3}{|l|}{ FIGO stage } \\
\hline $\mathrm{I}_{\mathrm{a} 1}-\mathrm{I}_{\mathrm{b} 2}$ & 115 & 44.57 \\
\hline $\mathrm{II}_{\mathrm{a} 1}-\mathrm{II}_{\mathrm{b}}$ & 125 & 48.45 \\
\hline $\mathrm{III}_{\mathrm{a}}$ & 18 & 6.98 \\
\hline \multicolumn{3}{|l|}{ Type of HPV infection } \\
\hline HPV16+ & 135 & 52.33 \\
\hline HPV18+ & 100 & 38.76 \\
\hline Other & 23 & 8.91 \\
\hline
\end{tabular}

SDS concentration of $1 \%$. This solution was then boiled at $100^{\circ} \mathrm{C}$ for $5 \mathrm{~min}$. A BCA protein concentration determination kit was used to determine the protein concentration. A total of $75 \mathrm{mg}$ total protein was loaded into each lane, separated by $15 \%$ SDS-PAGE and transferred to PVDF membranes. Membranes were blocked with $5 \%$ bovine serum albumin (P007; Beyotime Institute of Biotechnology) for $1 \mathrm{~h}$ in room temperature. Then membranes were incubated with anti-TF or anti- $\beta$-actin antibodies overnight at $4^{\circ} \mathrm{C}$ (both dilution 1:1,000) and then washed three times with PBS (each time $10 \mathrm{~min}$ ). Following this the membranes were incubated with goat anti-rabbit secondary antibodies (dilution 1:3,000) for $1 \mathrm{~h}$ at room temperature. The ECL luminescent liquid was used for visualization. The expression of the target protein was analyzed by Image J v1.8.0 software (National Institutes of Health, Bethesda, MD, USA) and the relative expression 

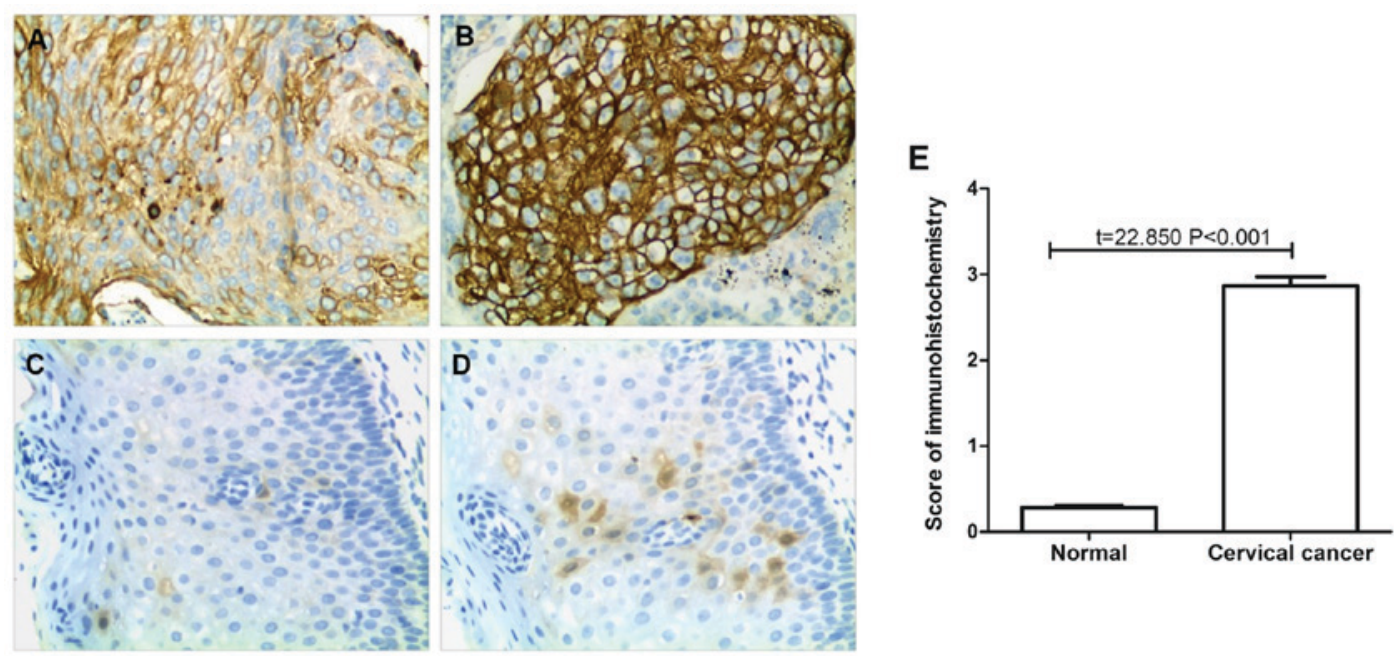

Figure 1. Detection of TF expression by immunohistochemistry. (A) Low TF expression in cervical cancer tissue. (B) High TF expression in cervical cancer tissue. (C) Negative TF expression in adjacent normal tissue. (D) Low TF expression in adjacent normal tissue. Magnification, x200. (E) Statistical analysis of the immunohistochemistry results. TF, tissue factor.

level of the target protein was characterized by the gray value of the target protein gray level compared with the $\beta$-actin protein band.

Statistical analysis. SPSS 20.0 software (IBM Corp., Armonk, NY, USA) was used for the statistical analysis of the data. The data were presented as the mean \pm standard deviation. A paired t-test was performed to compare the TF expression differences between cervical cancer tissues and the adjacent normal tissues. An independent sample t-test was performed two compare two samples and one-way analysis of variance, followed by Ducan's test, was used to compare differences between multiple groups. A $\chi^{2}$ test was also used to compare differences between groups. $\mathrm{P}<0.05$ was considered to indicate a statistically significant difference.

\section{Results}

Detection of TF expression by immunohistochemistry. TF proteins were observed as being localized to the cell membrane. The expression of TF in 258 paired cervical cancer and adjacent normal tissues was detected by immunohistochemistry. The results revealed that TF expression was significantly reduced in the adjacent normal tissues compared with the cervical cancer tissues $(\mathrm{P}<0.001$; Fig. 1$)$. In 73 normal tissue samples the immunohistochemical score was 1 and in the remaining 185 samples the score was 0 ; the normal tissue mean immunohistochemical score was $0.28 \pm 0.45$. TF had low expression in 171 of the cervical cancer samples, while it was highly expressed in 87 cases. There were 15, 50, $57,49,47$ and 40 cases with immunohistochemical scores of $0,1,2,3,4$ and 6 , respectively. The average score of immunohistochemistry was $2.86 \pm 1.76$ in the cervical cancer tissues.

Association between TF expression and the characteristics of patients with cervical cancer. The 258 cervical cancer tissue samples were divided into two groups according to their expression of TF as determined by immunohistochemistry.
There were 87 cases in the TF high expression group (immunohistochemical score $\geq 4$ ) and 171 cases in the TF low expression group (immunohistochemical score $<4$ ). The results revealed that the expression of TF in cervical cancer tissue was not significantly associated with age, HPV infection type, tumor classification, tumor growth type, tumor size or the degree of differentiation (Table II). However, TF expression was significantly associated with the metastasis of cervical cancer and the FIGO clinical stages $(\mathrm{P}<0.05$; Table II).

Association between TF expression and the clinical stage of cervical cancer. The expression of TF in 115 cases of phase I, 125 cases of phase II and 18 cases of phase III cervical cancer were compared by immunohistochemistry (Table III). The results revealed that the mean immunohistochemical scores in stage I, II and III cervical cancer tissues, were $2.35 \pm 1.84,3.08 \pm 1.65$ and $4.50 \pm 1.42$, respectively. The immunohistochemical score significantly increased as the cancer stage increased $(\mathrm{P}<0.01$; Fig. $2 \mathrm{E})$ Western blot analysis revealed that the relative expression of TF in the stage I, II and III cervical cancer tissues were $0.23 \pm 0.17,0.31 \pm 0.21$ and $0.46 \pm 0.32$, respectively (Fig. $2 \mathrm{~F}$ ). As the cancer stage increased the protein expression of TF significantly increased $(\mathrm{P}<0.01$; Fig. 2). These results indicated that increased $\mathrm{TF}$ expression may promote cervical cancer progression.

Association between TF expression and cervical cancer cell lymph node metastasis. The expression of TF was compared between cervical cancer tissues from patients with or without lymph node metastasis (Table IV). The results of the immunohistochemistry analysis revealed that the mean expression of $\mathrm{TF}$ in cervical cancer with lymph node metastasis was $3.55 \pm 1.48$, which was significantly increased compared with individuals without lymph node metastasis, whose mean TF expression was $2.27 \pm 1.77$ ( $\mathrm{P}<0.05$; Fig. 3$)$. The results of the western blot analysis demonstrated that the relative protein expression of TF in tumor tissues from patients with lymph 
Table II. Association between TF expression and clinical characteristics in patients with cervical cancer.

TF expression

Characteristic

Low $(\mathrm{n}=171)$

$\operatorname{High}(\mathrm{n}=87)$

$\chi^{2}$

P-value

Age (years)

$\geq 45$

37

0.113

0.737

$<45$

102

50

Clinical classification

Squamous cell carcinoma

139

64

2.417

0.299

Adenocarcinoma

27

18

Adenosquamous carcinoma

5

5

Tumor growth type

Cauliflower

107

53

1.716

0.633

Nodular

32

20

Ulcer

21

7

Erosive

11

7

Tumor size $(\mathrm{cm})$

$\leq 4$

Differentiation degree
Poor

Moderate

High

Lymph node metastasis

Yes

No

Distal metastasis

Yes

No

FIGO stage

$\mathrm{I}_{\mathrm{a} 1}-\mathrm{I}_{\mathrm{b} 2}$

$83 \quad 32$

7.952

0.019

$\mathrm{II}_{\mathrm{a} 1}-\mathrm{II}_{\mathrm{b}}$

81

44

III $_{\mathrm{a}}$

Type of HPV infection

$\begin{array}{lll}\text { HPV16+ } & 89 & 46 \\ \text { HPV18+ } & 70 & 30 \\ \text { Other } & 12 & 11\end{array}$

Table III. Tissue factor expression in cervical cancer tissue at

node metastasis was $0.41 \pm 0.19$, which was significantly increased compared with patients without lymph node metastasis (0.23 \pm 0.18 ; $\mathrm{P}<0.05$; Fig. 3).

Association between TF expression and distant metastasis in cervical cancer cells. The expression of TF was compared between cervical cancer tissues from patients with and without distant metastasis (Table V). The results of the immunohistochemistry analysis revealed that the mean TF expression scores in the tumor tissues of patients with distant metastasis of cervical cancer was 3.22 \pm 1.71 , which was significantly increased compared with patients without metastasis, who had a mean score of $2.43 \pm 1.72$ $(\mathrm{P}<0.05$; Fig. 4). The results of the western blot analysis different clinical stages.

\begin{tabular}{lrrrrrr}
\hline & \multicolumn{5}{c}{ Immunohistochemical score } \\
\cline { 2 - 7 } FIGO stage & \multicolumn{1}{c}{0} & \multicolumn{1}{c}{1} & 2 & 3 & 4 & 6 \\
\hline $\mathrm{I}_{\mathrm{a} 1}-\mathrm{I}_{\mathrm{b} 2}$ & 15 & 25 & 28 & 15 & 20 & 12 \\
$\mathrm{II}_{\mathrm{a} 1}-\mathrm{II}_{\mathrm{b}}$ & 0 & 25 & 29 & 27 & 24 & 20 \\
$\mathrm{III}_{\mathrm{a}}$ & 0 & 0 & 0 & 7 & 3 & 8 \\
\hline
\end{tabular}

demonstrated that the relative protein expression of TF in tumor tissues with distant metastasis of cervical cancer was 
Table IV. Tissue factor expression in patients with and without lymph node metastasis of cervical cancer.

\begin{tabular}{lrlcccr}
\hline \multirow{2}{*}{$\begin{array}{l}\text { Lymph } \\
\text { node } \\
\text { metastasis }\end{array}$} & \multicolumn{5}{c}{ Immunohistochemical score } \\
\cline { 2 - 7 } & 0 & 1 & 2 & 3 & 4 & 6 \\
\hline Yes & 2 & 20 & 31 & 37 & 35 & 28 \\
No & 13 & 30 & 26 & 12 & 12 & 12 \\
\hline
\end{tabular}

Table V. Tissue factor expression in patients with and without distant metastasis of cervical cancer.

\begin{tabular}{lrrrrrr}
\hline & \multicolumn{5}{c}{ Immunohistochemical score } \\
\cline { 2 - 7 } $\begin{array}{l}\text { Distant } \\
\text { metastasis }\end{array}$ & 0 & 1 & 2 & 3 & 4 & 6 \\
\hline Yes & 4 & 21 & 27 & 32 & 31 & 27 \\
No & 11 & 29 & 30 & 17 & 16 & 13 \\
\hline
\end{tabular}

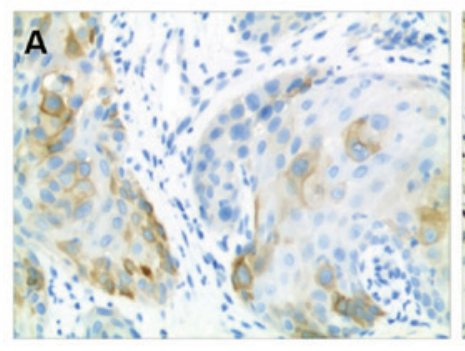

D

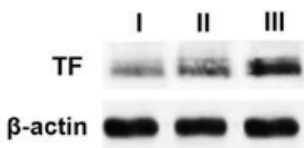

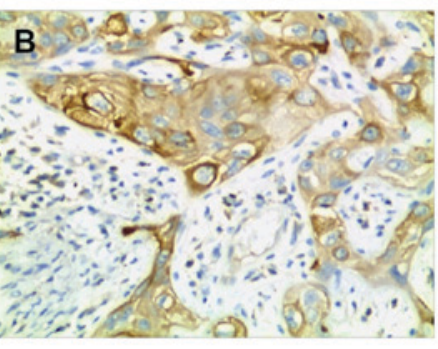

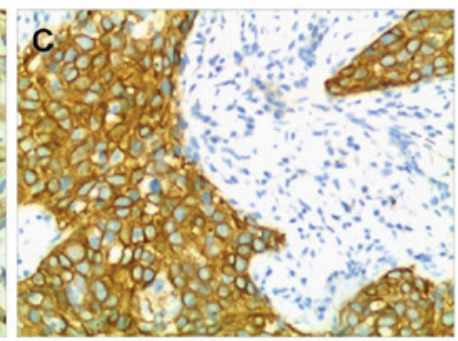

E

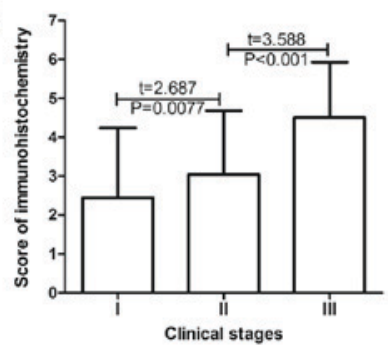

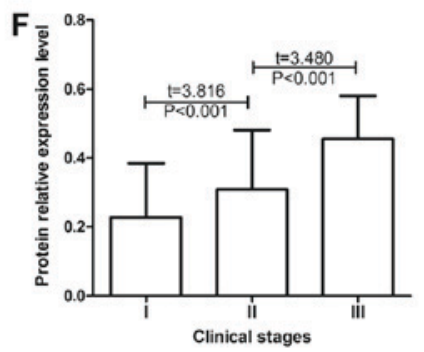

Figure 2. TF expression is elevated in association with the clinical stage of cervical cancer. Expression of TF in stage (A) $\mathrm{I}_{\mathrm{a} 1}-\mathrm{I}_{\mathrm{b} 2}$, (B) $\mathrm{II}_{\mathrm{a} 1}-\mathrm{II}_{\mathrm{b}}$ and $(\mathrm{C}) \mathrm{III}_{\mathrm{a}}$ cervical cancer tissue. Magnification, x200. (D) TF protein expression in tumor tissues at different clinical stages of cervical cancer as determined by western blot analysis. Statistical analysis of the (E) immunohistochemistry and (F) western blotting. TF, tissue factor.

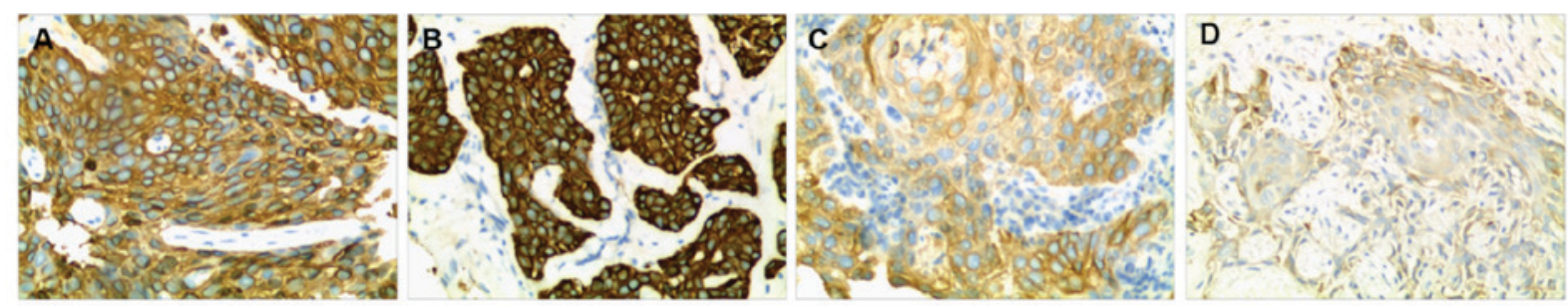

$\mathrm{E}$

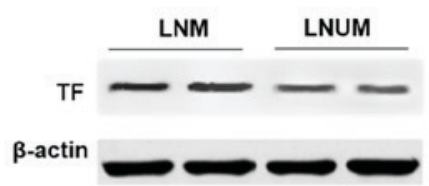

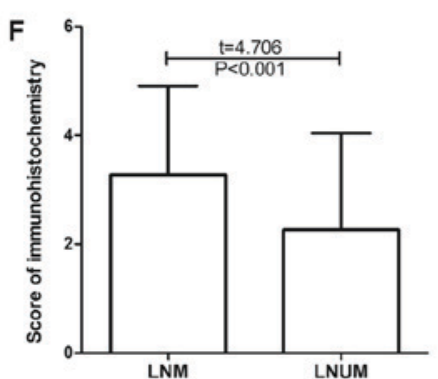

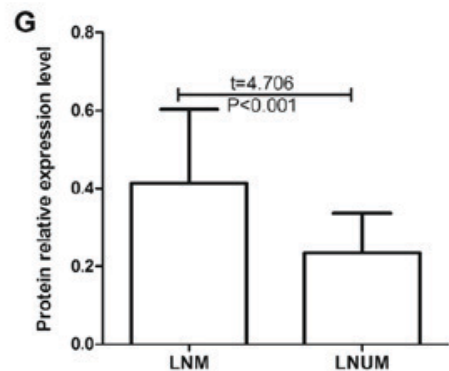

Figure 3. Association of TF expression with cervical cancer cell lymph node metastasis. (A and B) Detection of TF in cervical cancer tissues of two representative patients with LNM by immunohistochemistry. (C and D) Detection of TF in cervical cancer tissues of two representative patients LNUM by immunohistochemistry. Magnification, x200. (E) Examination of TF expression in tumor tissue from patients with and without LNM as determined by western blot analysis. Statistical analysis of $(\mathrm{F})$ immunohistochemistry and $(\mathrm{G})$ western blotting. LNM, lymph node metastasis; LNUM, without lymph node metastasis; TF, tissue factor.

$0.38 \pm 0.15$, which was significantly increased compared with samples from patients without distal metastases $(0.23 \pm 0.16$; $\mathrm{P}<0.05$; Fig. 4).

\section{Discussion}

Within the human body TF has the strongest influence on the 

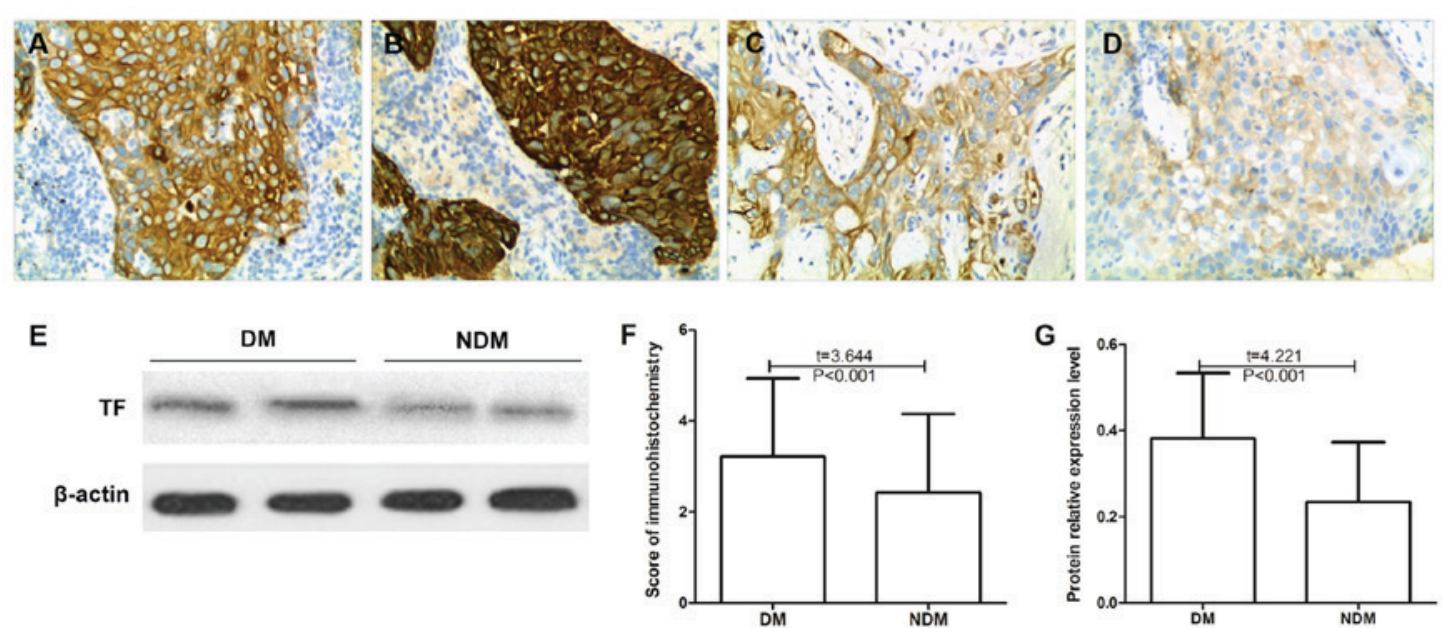

Figure 4. Association of TF expression with distal metastasis of cervical cancer cells. (A and B) TF expression in two representative cases of cervical cancer with DM as detected by immunohistochemistry. (C and D) TF expression in two representative cases of cervical cancer NDM as detected by immunohistochemistry. Magnification, x200. (E) TF protein expression in tumor tissue of patients with and without DM as determined by western blotting. Statistical analysis of (F) immunohistochemistry and (G) western blotting. DM, distal metastasis; TF, tissue factor; NDM, without distal metastasis.

promotion of blood coagulation. Under normal physiological conditions the blood mononuclear and vascular endothelial cells do not express TF (13). However, when tissue injury occurs, cytokine stimulation or inflammatory reactions cause the abundant expression of TF (13). TF is the only transmembrane protein expressed on the surface of the cell, which serves a role in coagulation and also serves a non-coagulation function as a receptor protein (13). TF in the blood of patients with malignant tumors may come from cancer cells (13). Although the specific molecular mechanisms associated with the development of malignant tumors are not clear, it has been determined that the high expression of TFs in the peripheral blood is closely associated with the invasion, metastasis, clinical stage and prognosis of malignant tumors (14).

In the present study it was revealed that the expression of TF was significantly increased in cervical cancer tissue compared with adjacent normal tissue. TF is a type of trace protein, which is widely expressed in various normal tissues; it is a transmembrane protein that consists of three parts, extracellular, transmembrane and cytoplasm (6,7). Under normal physiological conditions, TF on the cell surface is in a silent state $(6,7)$. However, it has been suggested that TF is induced by tumor necrosis factor, tumor cells or the tumor-specific microenvironment and activated on the surface of tumor cells in ovarian cancer (15), gastric cancer (16) and breast cancer (17) and therefore exhibits abnormally high expression on the surface of tumor cells. Lo et al (16) observed that TF was highly expressed in gastric cancer tissues. Lo et al also demonstrated that the TF expression level increased with the clinical stage in gastric cancer, which suggests that the expression of TF in malignant tumor tissues may be associated with the progression of malignant tumors. Therefore, the present study further analyzed the potential association between TF expression and patient characteristics in cervical cancer tissues.

The present study demonstrated that TF expression was significantly associated with metastasis of cervical carcinoma cells (lymph node and distal metastasis) and FIGO stage. The protein expression of TF was significantly increased in patients with metastatic cervical carcinoma compared with patients with non-metastatic carcinoma. The occurrence and development of malignant tumors is a multi-step process, which is caused by multiple internal factors, including gene mutation, and external factors, including drug effects and environmental pollution.

In recent years, it has been reported that TF primarily affects the invasion and migration of tumor cells via the coagulation and non-coagulation pathways (18). Tumor cells may activate the coagulation system in patients, resulting in the development of a hypercoagulable state in patients with malignant tumors, particularly those at an advanced stage (19). In these patients, increased blood viscosity and slowed blood flow reduce the mechanical damage of tumor cells due to microvascular compression, and the microenvironment is more favorable to the formation of tumor thrombus and invasion and metastasis of cancer cells $(20,21)$. This may enhance the development of malignant tumors, which suggests that the activation of the coagulation system in certain patients with malignant tumors is closely associated with clinical stage and prognosis $(13,22)$. TFs facilitate the signal transduction of transmembrane proteins in and out of tumor cells and therefore have a greater impact compared with non-transmembrane proteins on the invasion and metastasis of tumor cells $(23,24)$. Previous studies have demonstrated that TF may be activated by forming complexes with coagulation factor VII or VIIa; together with protease activated receptor (PAR)-1 or PAR-2 these complexes may mediate signal transduction within and outside tumor cells $(23,24)$. Chanakira et al $(23)$ revealed that the TF/VIIa complex activates PAR-2 to increase the chemotactic migration of epithelial ovarian tumor cells, and in turn promotes disease progression. In addition, in different tumor tissues TF is activated by different signals and activates different PAR proteins, which mediates the conduction of different signaling pathways $(25,26)$. Previous studies have demonstrated that TF may mediate signaling pathways, including nuclear factor-kb, mitogen-activated protein kinase and alanine aminotransferase to promote tumor cell metastasis $(25,26)$.

In conclusion, TF is highly expressed in cervical cancer tissues and the high expression of TF may promote cervical cancer progression by enhancing the invasive and migratory abilities of cervical cancer cells. 


\section{Acknowledgements}

Not applicable.

\section{Funding}

No funding was received.

\section{Availability of data and materials}

The datasets used and/or analyzed during the current study are available from the corresponding author on reasonable request.

\section{Authors' contributions}

XiaZ contributed to the conception and design of the study. $\mathrm{XitZ}$ analyzed and interpreted the patient data regarding the hematological disease and the transplant. CC, JG, TY, YQ and $\mathrm{XD}$ performed the histological examination of cervical cancer tissues. XiaZ and XitZ were major contributors in writing the manuscript. All authors read and approved the final manuscript.

\section{Ethics approval and consent to participate}

All patients included in the present study provided written informed consent prior to their inclusion. The study was approved by the Ethics Committee of West China Second Hospital.

\section{Patient consent for publication}

Not applicable.

\section{Competing interests}

The authors declare that they have no competing interests.

\section{References}

1. Chen W, Zheng R, Baade PD, Zhang S, Zeng H, Bray F, Jemal A, Yu XQ and He J: Cancer statistics in china, 2015. CA Cancer J Clin 66: 115-132, 2016.

2. Chen W, Zheng R, Zhang S, Zeng H, Zuo T, Xia C, Yang Z and He J: Cancer incidence and mortality in china in 2013: An analysis based on urbanization level. Chin J Cancer Res 29: 1-10, 2017.

3. Di J, Rutherford S and Chu C: Review of the cervical cancer burden and population-based cervical cancer screening in China. Asian Pac J Cancer Prev 16: 7401-7407, 2015.

4. Wang W, Chu HJ, Liang YC, Huang JM, Shang CL, Tan H, Liu D, Zhao YH, Liu TY and Yao SZ: FABP5 correlates with poor prognosis and promotes tumor cell growth and metastasis in cervical cancer. Tumour Biol 37: 14873-14883, 2016.

5. LiZ, Yang Y, Gao Y, Wu X, Yang X, Zhu Y, Yang H, Wu L, Yang C and Song L: Elevated expression of flotillin-1 is associated with lymph node metastasis and poor prognosis in early-stage cervical cancer. Am J Cancer Res 6: 38-50, 2015.

6. Claussen C, Rausch AV, Lezius S, Amirkhosravi A, Davila M, Francis JL, Hisada YM, Mackman N, Bokemeyer C, Schmalfeldt B, et al: Microvesicle-associated tissue factor procoagulant activity for the preoperative diagnosis of ovarian cancer. Thromb Res 141: 39-48, 2016.

7. Otero LL, Alonso DF, Castro M, Cinat G, Gabri MR and Gomez DE: Tissue factor as a novel marker for detection of circulating cancer cells. Biomarkers 16: 58-64, 2011.

8. Yu YJ, Hou XD and Li YM: Effect of tissue factor knockdown on the growth, invasion, chemoresistance and apoptosis of human gastric cancer cells. Exp Ther Med 7: 1376-1382, 2014.
9. Xu Y, Qin X, Zhou J, Tu Z, Bi X, Li W, Fan X and Zhang Y: Tissue factor pathway inhibitor-2 inhibits the growth and invasion of hepatocellular carcinoma cells and is inactivated in human hepatocellular carcinoma. Oncol Lett 2: 779-783, 2011.

10. Geddings JE, Hisada Y, Boulaftali Y, Getz TM, Whelihan M, Fuentes R, Dee R, Cooley BC, Key NS, Wolberg AS, et al: Tissue factor-positive tumor microvesicles activate platelets and enhance thrombosis in mice. J Thromb Haemost 14: 153-166, 2016.

11. Eisenreich A, Bolbrinker $\mathrm{J}$ and Leppert $\mathrm{U}$ : Tissue factor: A conventional or alternative target in cancer therapy. Clin Chem 62: 563-570, 2016.

12. Zhang Y, You L, Chen J and Mao C: Expression of kinesin family member 3B is associated with poor prognosis in epithelial ovarian cancer patients. Int J Clin Exp Pathol 10: 2834-2842, 2017.

13. Kasthuri RS, Taubman MB and Mackman N: Role of tissue factor in cancer. J Clin Oncol 27: 4834-4838, 2009.

14. Unruh D, Sagin F, Adam M, Van Dreden P, Woodhams BJ, Hart K, Lindsell CJ, Ahmad SA and Bogdanov VY: Levels of alternatively spliced tissue factor in the plasma of patients with pancreatic cancer may help predict aggressive tumor phenotype. Ann Surg Oncol 3 (Suppl 22): S1206-S1211, 2015.

15. Cocco E, Varughese J, Buza N, Bellone S, Lin KY, Bellone M, Todeschini P, Silasi DA, Azodi M, Schwartz PE, et al: Tissue factor expression in ovarian cancer: Implications for immunotherapy with hI-con1, a factor VII-IgGF(c) chimeric protein targeting tissue factor. Clin Exp Metastasis 28: 689-700, 2011.

16. Lo L, Valentine H, Harrison J, Hayes S, Welch I, Pritchard S, West C and Ang Y: Tissue factor expression in the metaplasiaadenoma-carcinoma sequence of gastric cancer in a european population. Br J Cancer 107: 1125-1130, 2012.

17. Schaffner F, Versteeg HH, Schillert A, Yokota N, Petersen LC, Mueller BM and Ruf W: Cooperation of tissue factor cytoplasmic domain and PAR2 signaling in breast cancer development. Blood 116: 6106-6113, 2010.

18. Golino P, Ragni M, Cimmino G and Forte L: Role of tissue factor pathway inhibitor in the regulation of tissue factor-dependent blood coagulation. Cardiovasc Drug Rev 20: 67-80, 2002.

19. Mego M, Karaba M, Minarik G, Benca J, Sedlácková T, Tothova L, Vlkova B, Cierna Z, Janega P, Luha J, et al: Relationship between circulating tumor cells, blood coagulation, and urokinase-plasminogen-activator system in early breast cancer patients. Breast J 21: 155-160, 2015.

20. Koizume S, Jin MS, Miyagi E, Hirahara F, Nakamura Y, Piao JH, Asai A, Yoshida A, Tsuchiya E, Ruf W and Miyagi Y: Activation of cancer cell migration and invasion by ectopic synthesis of coagulation factor VII. Cancer Res 66: 9453-9460, 2006.

21. Ma YY, He XJ, Wang HJ, Xia YJ, Wang SL, Ye ZY and Tao HQ: Interaction of coagulation factors and tumor-associated macrophages mediates migration and invasion of gastric cancer. Cancer Sci 102: 336-342, 2011.

22. Li W, Xu S, Lin S and Zhao W: Overexpression of runt-related transcription factor- 2 is associated with advanced tumor progression and poor prognosis in epithelial ovarian cancer. J Biomed Biotechnol 2012: 456534, 2012

23. Chanakira A, Westmark PR, Ong IM and Sheehan JP: Tissue factor-factor VIIa complex triggers protease activated receptor 2-dependent growth factor release and migration in ovarian cancer. Gynecol Oncol 145: 167-175, 2017.

24. Ribeiro FS, Simão TA, Amoêdo ND, Andreollo NA, Lopes LR, Acatauassu R, Rumjanek FD, Albano RM, Pinto LF and Monteiro RQ: Evidence for increased expression of tissue factor and protease-activated receptor-1 in human esophageal cancer. Oncol Rep 21: 1599-1604, 2009.

25. Luan L, Yang $Z$ and Tan J: Tissue factor and circulating tumor cells. Tumor 35, no. 5, 2015.

26. Yang HP, Yue L, Jiang WW, Liu Q, Kou JP and Yu BY: Diosgenin inhibits tumor necrosis factor-induced tissue factor activity and expression in THP-1 cells via down-regulation of the NF- $\mathrm{kB}$, Akt, and MAPK signaling pathways. Chin J Nat Med 11: 608-615, 2013.

This work is licensed under a Creative Commons Attribution-NonCommercial-NoDerivatives 4.0 International (CC BY-NC-ND 4.0) License. 